\title{
Correlation of genetic instability and apoptosis in the presence of oncogenic Ki-Ras
}

\author{
Chang-Yan Chen ${ }^{1}$, James Liou', Lora W. Forman ${ }^{1}$ \\ and Douglas V. Faller ${ }^{1,2}$ \\ 1 Cancer Research Center, and Departments of Medicine, Biochemistry, \\ Pediatrics, Microbiology, Pathology and Laboratory Medicine, Boston \\ University School of Medicine, Boston, Massachusetts 02118, USA \\ ${ }^{2}$ Corresponding author: Dr. Douglas V. Faller, Cancer Research Center, Boston \\ University School of Medicine, 80 E. Concord St. K-701, Boston, \\ Massachusetts 02118, USA tel: (617) 638-5603; fax: (617) 638-4176; \\ e-mail address: dfaller@bu.edu
}

Received 9.2.98; revised 2.6.98; accepted 10.8.98

Edited by D. Green

\begin{abstract}
The product of the ras proto-oncogene has been implicated as an essential signal transducer, involved in a variety of biological or pathological activities, including apoptosis. The aim of this investigation was to further explore the mechanisms of apoptosis triggered by Ras. Stable expression of constitutively-activated ( $v$-) Ki-Ras in Balb/c3T3 mouse fibroblasts resulted in a loss of $G_{1}$ arrest in response to treatments which induced cell cycle arrest in the parental Balb/c-3T3 cells, accompanied by decreased expression of the p53 tumor suppressor protein and the GADD45 gene, the product of which is involved in DNA repair, and deregulated expression of the MDM-2 gene, the product of which can regulate p53 expression. Ki-Ras expression also increased the frequency of PALA-selectable $C A D$ gene amplification, and paradoxically the susceptibility to PALA-induced apoptosis. After persistent serum-starvation, cells expressing the activated ras gene lost clonogenic potential, indicating impaired capability for genetic repair in the cells. Taken together, these data suggest that activated Ki-ras may confer genetic instability upon cells, possibly through interference with tumor suppressors, such as $\mathrm{p} 53$. While this instability may facilitate adaptation to environmental stresses, this instability in the genome also renders cells containing activated ras genes intrinsically more susceptible to programmed cell death, possibly by accumulation of undesirable or lethal genetic events during the process of tumor development.
\end{abstract}

Keywords: ras oncogene; p53; genomic instability; $C A D$ gene amplification; clonogenicity; apoptosis; tumor suppressors

Abbreviations: PALA, N-phosphonacetyl-L-aspartate; DME, Dulbecco Modified Eagle Medium; PE, planing efficiency; MEF, mouse embryo fibroblast

\section{Introduction}

The members of the ras gene family, Ha-ras, Ki-ras and $\mathrm{N}$-ras, encode $21 \mathrm{kDa}$ guanine nucleotide-binding proteins. Ras proteins have been found to be involved in the regulation of many cellular biological or pathological processes, such as proliferation and differentiation, as well as apoptosis (Barbacid, 1987; Bourne et al, 1990; Downward et al, 1990; Li et al, 1992; Marshall, 1993; Chen and Faller, 1995, 1996). Although the direct targets of Ras proteins are not entirely defined, many downstream effectors of the Ras signaling pathway have been suggested (Hattori et al, 1992; Zhang et al, 1992; Buday and Downward, 1993; Medema et al, 1993; Votjtek et al, 1993; Harrington et al, 1994). Ras proteins can be activated in response to a wide variety of mitogenic or activation stimuli (Avruch et al, 1994; McCormick, 1994), and suppression of Ras activity using either dominantnegative mutants of Ras or neutralizing anti-Ras antibodies efficiently blocks entry of cells into S-phase after growth factor stimulation (Moodie et al, 1993; Khosravi-Far and Der, 1994; Winston et al, 1996). Recently, many studies have suggested that expression of oncogenic Ras may be associated with multiple genetic alterations which contribute to initiation of abnormal karyotype, deregulation of cell growth, development of cancer, and perhaps susceptibility to apoptosis (Hirakawa and Ruley, 1988; Li et al, 1992; de Vries et al, 1993; Denko et al, 1994; Arber et al, 1996; Chen and Faller, 1996; Chen, et al, 1998). However, the mechanisms by which oncogenic Ras induces these seemingly disparate genetic alterations remain poorly understood.

One of the early and common characteristics of tumor cells is genetic instability. The reconstructed genome arising during tumor development allows cells to escape from normal restriction against unlimited proliferation and metastasis (Hartwell and Weinert, 1989; Hartwell, 1992; Hattori et al, 1992; Hartwell and Kastan, 1994; Sherr and Roberts, 1995). Studies in yeast have demonstrated that genetic alternations in DNA damage repair processes, in the machinery for DNA replication, and in cell cycle controls, all contribute to genomic instability (Hartwell, 1992). Mutations in the tumor suppressor gene encoding p53 is the most common event in human malignancies and occurs in at least $50 \%$ of human cancers (Hartwell, 1992; Harris and Hollstein, 1993). A number of properties of wtp53 related to its growth-regulatory function, inducing sitespecific transcriptional transactivation, are also associated with its tumor-suppressive functions. For example, wt-p53 can reverse the transformed phenotype when cotransfected into primary rat embryonic fibroblasts with various combinations of oncogenes, such as ras plus myc, ras plus adenovirus E1A, E1A plus E1B, and ras plus human papillomavirus E7 (Storey et al, 1988; Eliyahu et al, 1989; Finlay et al, 1989; Phelps et al, 1989). wt-p53 is involved in the regulation of cell cycle checkpoints, especially G1/S 
transition. Disruption of such checkpoints would impair timely repair of cellular or DNA damage, and contribute to the potential loss of genomic material (Kastan et al, 1992; Marx, 1994; Wang et al, 1995). Inactivation of wt-p53 in various types of cells has been demonstrated to accompany an increase incidence of gene amplification (for example $C A D$ gene amplification), and such gene amplification is an indicator of the unstable genomic status of these cells (Livingstone et al, 1992; Yin et al, 1992; Carder et al, 1993; Schaefer et al, 1993; Lee et al, 1994; Bouffler et al, 1995; Donehower et al, 1995). As a transcription factor, wt-p53 appears to control the expression of many genes, including a repair-related gene GADD45 (Kastan, et al, 1992). GADD45 gene was found to be rapidly induced by DNA-damaging agents or other conditions eliciting cell growth arrest, such as serum starvation, in a wide variety of mammalian cells expressing wt-p53, and the GADD45 gene product may participate in the process of cellular or DNA damage repair.

Normal or untransformed cells, such as fibroblasts and lymphocytes, arrest in the $\mathrm{G} 1 / \mathrm{G} 0$ phase of the cell cycle in response to serum-depletion, inhibition of PKC activity, or exposure to PALA (N-phosphonacetyl-L-aspartate), an inhibitor of purine metabolism. During serum or mitogen withdrawal, constitutively-expressed c-myc may inappropriately drive cells into cell cycle and initiate the apoptotic process (Askew, et al, 1991; Shi, et al, 1992; Evan, et al, 1992). Oncogenic Ras can trigger cells to undergo apoptosis following downregulation of PKC activity (Chen and Faller, 1995). Recent studies have show that expression of activated Ras in fibroblasts or lymphocytes results in elevation of certain $\mathrm{G} 1$ cyclins, and subsequently alters cell cycle progression (Filmus et al, 1994; Lovec et al, 1994; Liu et al, 1995; Arber et al, 1996; McKenna et al, 1996; Winston et al, 1996). Overexpression of $p 16$, a cyclin inhibitor, blocks Ras-mediated proliferation and the transformation caused by introduction of activated ras genes into primary murine fibroblasts lacking p16 (Serrano et al, 1995, 1997).

To further study the function of oncogenic Ras in the regulation of cell proliferation and cell death, we have used early passage mouse Balb/c-3T3 fibroblast lines which were stably-expressing a $v$-Ki-ras gene (designated Ki-Balb cell lines) to seek correlations among the expression of the tumor suppressor p53, genetic instability induced by Ras, and the susceptibility to programmed cell death conferred by oncogenic Ras. We show in this report that, in the presence of activated Ki-ras, cells cannot arrest in the G1phase of cell cycle in response to treatments which induce cell cycle arrest in the parental Balb/c-3T3 cells. This loss of a cell cycle checkpoint is accompanied by decreases in the expression of the p53 protein and the GADD45 gene. Analysis of $C A D$ (trifunctional enzyme carbamoyl-P synthetase, aspartate transcarbamylase, dihydro-orotase) gene amplification and analysis of cell viability in the presence of PALA revealed that activated Ki-ras increased both the frequency of $C A D$ gene amplification and the susceptibility of these cells to apoptosis. Clonogenicity assays demonstrated that cells expressing $v$-Ki-ras lost the capability to propagate following periods of serum-deple-

tion. The combination of serum withdrawal and PALA exposure abolished the ability of $K i$-Balb cells to form PALA-resistant colonies and increased their susceptibility to PALA-induced apoptosis. These studies provide a framework for understanding the correlation between multiple genetic changes in the presence of the ras oncogene and the susceptibility to apoptosis under certain environmental conditions.

\section{Results \\ Oncogenic Ki-Ras prevents $\mathrm{G}_{1}$ arrest during serum-depletion}

Activated ( $v$-) Ki-ras were introduced into murine Balb/c-3T3 fibroblast cell lines stable-infection (designated $K i$-Balb cell lines). To assess cell cycle regulation in the presence or absence of serum in Ki-Balb cells in comparison to the parental Balb-3T3 cells, and to investigate the potential role of activated $K i$-Ras in this process, nuclear DNA profiles of Balb and $K i$-Balb cells, growing in medium containing either 10 or $0.05 \%$ of newborn calf serum for $48 \mathrm{~h}$, were examined (Figure 1). After $48 \mathrm{~h}$ of serum-starvation, the majority of Balb-3T3 cells were arrested in the G0/G1-phase. A significant proportion of $K i$-Balb cells, however, after $48 \mathrm{~h}$ of serumstarvation, remained in the $S$ and $\mathrm{G} 2 / \mathrm{M}$-phases, although the proportion of actively growing cells $(\mathrm{S}+\mathrm{G} 2 / \mathrm{M})$ was reduced in comparison with the same cells cultured in medium containing $10 \%$ serum. These results indicate that there is a disruption of growth arrest in cells expressing Ki-Ras cells after serumdepletion.

Balb in $10 \%$ serum

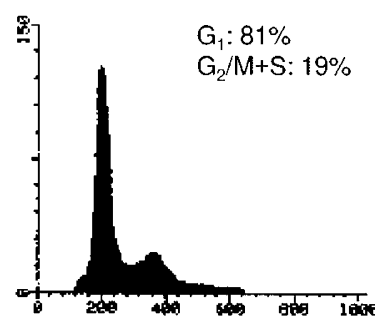

Balb in $0.05 \%$ serum

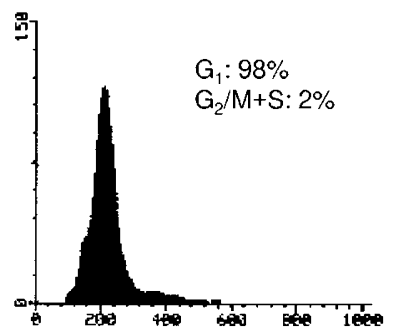

Figure 1 DNA profiles of Balb fibroblasts, with or without oncogenic Ki-Ras under normal growth conditions or after $48 \mathrm{~h}$ of serum-depletion. The percentages of cells in $\mathrm{G} 1, \mathrm{~S}$, and $\mathrm{G} 2 / \mathrm{M}$ are indicated 


\section{Expression of wt-p53 is decreased in cells expressing Ki-Ras}

As p53 has been implicated in the regulation of cell cycle arrest and apoptosis (Livingstone et al, 1992; Vogelstein and Kinzler, 1992; Yin et al, 1992; Prives, 1993, 1994; Moll et al, 1996), the expression of wt-p53 protein in the nuclear-free cell lysate fraction and in the nuclear fraction of Balb and Ki-Balb cells was examined under normal growth conditions or after serum-starvation for $48 \mathrm{~h}$ (Figure 2a). Equal amounts of proteins from either the nuclear-free cell lysate or the nuclear fraction of the two cell types were immunoprecipitated, and subsequently immunoblotted, with an anti-wt-p53 antibody. wt-p53 protein was detectable in both subcellular fractions of Balb cells under normal growth conditions (Figure 2a, lanes 1 and 5), and was increased (by 2-2.8-fold) in both fractions after $48 \mathrm{~h}$ of serum-starvation (Figure 2a, lanes 2 and 6 ). wtp53 protein in the nuclear-free cell lysate fraction or in the nuclear fraction of Ki-Balb cells was almost undetectable under normal growth conditions (Figure 2a, lanes 3 and 7). Following $48 \mathrm{~h}$ of culture in serum-depleted medium, there was only a minimal and non-significant increase (less than 0.5 -fold) in the level of wt-p53 protein in the cell lysate (Figure 2a, lane 4), and no change in the nuclear fraction (Figure 2a, lane 8) in Ki-Balb cells. The same phenomenon has been observed in a human T lymphoblastoid cell line, Jurkat. wtp53 protein is undetectable in Jurkat cells expressing activated Ras during normal growth or after exposure to agents capable of inducing $\mathrm{G} 1$ arrest in parental Jurkat cells (data not shown). A number of different Ki-Balb clonal cell

a
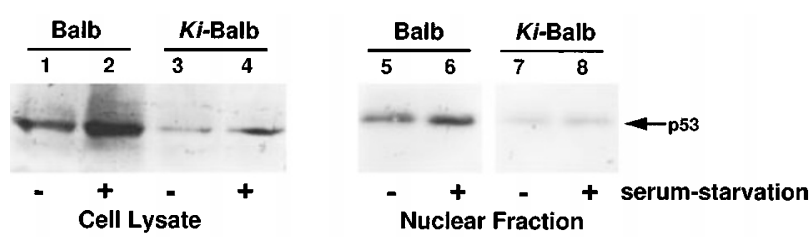

b

\section{myc-Balb}

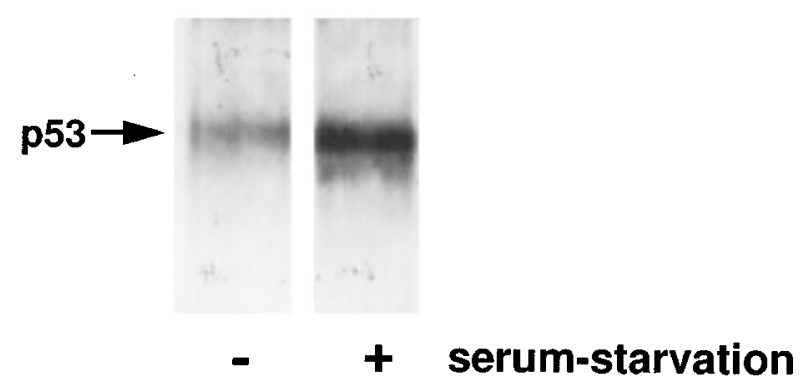

Figure 2 The expression of wt-p 53 protein with or without expression of an activated ras or myc gene following serum-starvation or under normal growth conditions. (a) The nuclear-free cell lysates or nuclear extracts of Balb and KiBalb cells, under conditions with $(+)$ or without $(-)$ serum-starvation were immunoprecipitated and subsequently immunoblotted for wt-p 53 expression. (b) The cell lysates of Balb cells transfected with oncogenic myc in the presence $(+)$ or absence $(-)$ of serum-starvation were immunoprecipitated and then immunoblotted for wt-53 expression lines and pools were tested for wt-p53 dysregulation, growth properties, sensitivity to serum-deprivation, clonogenicity and PALA sensitivity (as described below), and all had identical phenotypes.

It is normally necessary to introduce two complementing oncogenes, such as myc and ras, to efficiently transform primary cells, and forced overexpression of c-Myc has been shown to promote apoptosis under certain conditions (Askew, et al, 1991; Shi, et al, 1992; Evan, et al, 1992). To determine if $m y c$ alone can also suppress the expression of wt-p53 protein, Balb cells were stablytransfected with the myc proto-oncogene (myc-Balb cells) and the levels of wt-p53 protein were examined in the cell lysates under normal growth conditions or after serumstarvation (Figure $2 b$ ). There was a low level of wt-p53 protein under normal growth conditions in the myc-Balb cells and the p53 protein level was dramatically increased after $48 \mathrm{~h}$ of serum-starvation ( $>$ threefold). Yet, like the cells expressing activated Ras, the myc-Balb cells were not arrested in cell cycle by serum-starvation (data not shown). Thus, the inability of cells expressing activated Ras to induce wt-p53 in response to serum deprivation is not due solely to their failure to become growth arrested, and conversely, the loss of wt-p53 inducibility in Ki-Balb cells may not be causally related to their failure to arrest cell cycle progression.

\section{Dysregulation of p53-regulated genes GADD45 and MDM-2 in cells expressing activated $K i$-Ras}

The mammalian GADD45 gene is highly conserved and can be induced by DNA damage and various other cellular stresses (Kastan et al, 1992). As a downstream effector of p53, the activity of the product of the GADD45 gene appears to be involved in enhancement of DNA repair and inhibition of cellular DNA synthesis (Walker, 1984; Fornace et al, 1988, 1989; Kastan et al, 1992; Smith et al, 1994). Since the expression of p53 protein was reduced in Ki-Balb cells, the expression of GADD45 gene was examined under normal growth conditions, or after serum-depletion, in Balb cells and Ki-Balb cells (Figure 3a). GADD45 mRNA was detectable under normal growth conditions, and significantly induced (threefold) after serum-depletion in Balb cells. In contrast, $\mathrm{Ki}$ Balb cells expressed no appreciable levels of GADD45 under either normal growth or serum-depleted conditions. This dysregulation of GADD45 expression therefore correlated with the observed disruption of p53 induction in these cells, and suggested that there might be a concurrent reduction of cellular damage repair capability in the presence of oncogenic Ki-Ras.

Deregulation of MDM-2 gene expression has been demonstrated in various human tumors and transformed mouse cell lines. MDM-2 transcription can be induced by wt-p53 (Cahilly-Snyder et al, 1987; Fakharzadeh et al, 1991). Conversely, the MDM-2 protein is a cellular inhibitor of p53, in that it can bind p53 and downregulate its activity (Momand et al, 1991; Chin et al, 1992; Prives, 1993). To determine if $M D M-2$ expression was altered in the setting of oncogenic KiRas, analysis of MDM-2 gene transcripts was conducted Ki-Balb cells (Figure $3 b$ ). MDM-2 mRNA was 
almost undetectable in Balb cells under normal growth conditions, but became abundant (6-8-fold induction) after serum-depletion. In contrast, appreciable amounts of $M D M$ 2 mRNA were expressed in Ki-Balb cells under normal growth conditions (1.8-fold higher than present in Balb cells), and there was no further induction of the MDM-2 gene by serum-depletion, raising the possibility that this dysregulation of $M D M-2$ gene induction may play a role in the disruption of p53 signaling observed in Ki-Balb cells, through disruption of the p53/MDM-2 autoregulatory feedback loop.

\section{Enhancement of CAD gene amplification in cells expressing oncogenic Ki-Ras}

Normal cells growth arrest in the presence of $\mathrm{N}$ (phosphonacetyl)-L-aspartate (PALA), a specific inhibitor of de novo uridine biosynthesis. Cells lacking wt-p 53 form

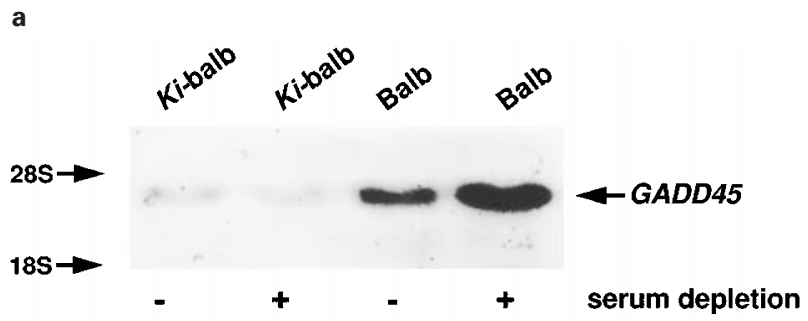

b

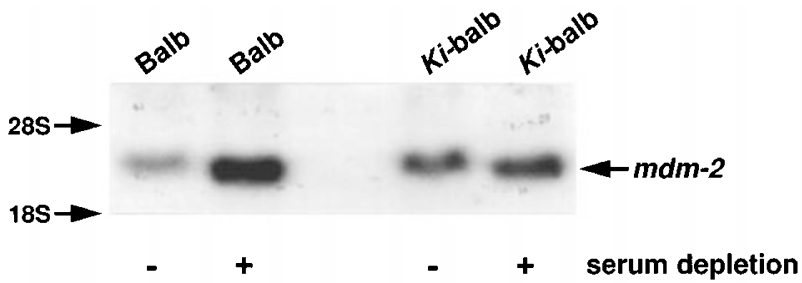

Figure 3 Induction of GADD45 and MDM-2 genes in the setting of serumdepletion. (a) Northern blot of GADD 45 mRNA message from Balb and Ki-Balb cells. Total RNA from the two cell types with $(+)$ or without $(-)$ serumstarvation were prepared, separated on an agarose gel, transferred to nitrocellulose, and probed with a ${ }^{32} \mathrm{P}$-labeled hamster GADD45 probe. (b). RNA blot of MDM-2 gene expression. Total RNA from Balb and Ki-Balb cells with $(+)$ or without $(-)$ serum starvation were prepared, transferred to nitrocellulose, and the blot was hybridized with a ${ }^{32} \mathrm{P}$-labeled murine MDM-2 specific probe. Equal loading of total RNA into each lane of the gel for each experiment was ensured by rehybridization of the blot with a $\beta$-actin probe (data not shown) colonies in PALA at high frequency, presumably through a mechanism in which the $C A D$ gene is amplified (Livingstone et al, 1992; Yin et al, 1992; Schaefer et al, 1993; Kelly et al, 1995). The $C A D$ gene encodes a single polypeptide chain containing carbamyl phosphate synthetase, dihydroorotase and aspartate transcarbamylase (which PALA inhibits). Amplification of genes like $C A D$ is facilitated under conditions of genetic instability (Windle et al, 1991; Stark et al, 1993). To investigate whether the loss of wt-p53 in KiBalb cells correlates with an increased frequency of $C A D$ gene amplification in response to PALA treatment, the plating efficiency, sensitivity to PALA, and CAD gene amplification potential were tested and compared between the control Balb and Ki-Balb cells. After determination of the plating efficiency for each cell type, the PALA concentration that inhibited $50 \%$ of colony formation $\left(L_{50}\right)$ was defined, and the frequency of colonies arising which were resistant to six times this concentration was measured (Table 1). PALA-resistant clones were not detected in $1 \times 10^{7}$ Balb cells in the presence of PALA $\left(6 \times L_{50}\right)$ (frequency of $<1$ / $10^{7}$ ), but 17 PALA-resistant colonies were generated from $1 \times 10^{6} \mathrm{~K}$-Balb cells (frequency of $>1 / 10^{5}$ ).

To verify that the $C A D$ gene was amplified in the PALAresistant clones, Southern blot analysis was conducted. Two resistant colonies of $K i$-Balb cells were isolated after selection with PALA. DNA from the drug-resistant clones, as well as DNA from normal control Balb cells, after 10 days of PALA treatment was prepared. Each PALAresistant clone of $K i$-Balb cells demonstrated amplified copies of the $C A D$ gene, whereas there was no $C A D$ gene amplification in the control Balb cells (Figure 4), demonstrating that $C A D$ gene amplification had occurred in the activated Ras-expressing cells.

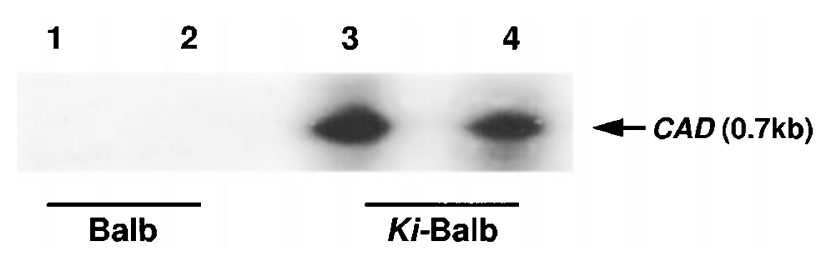

Figure $4 C A D$ gene amplification in the presence of PALA. DNAs were isolated from Balb cells (lanes 1 and 2), and two PALA-resistant Ki-Balb clones (lanes 3 and 4 ) after selection in $30 \mu \mathrm{M}$ of PALA for Balb cells and $90 \mu \mathrm{M}$ of PALA for Ki-Balb cells. DNAs were normalized after restriction digestion, separated on an agarose gel, and hybridized with a $0.3 \mathrm{~kb}$ mouse $C A D$ cDNA probe, a product of PCR

Table 1 Gene amplification in Balb and Ki-Balb mouse fibroblasts

\begin{tabular}{|c|c|c|c|c|c|c|}
\hline Cell & PE (\%) & p53 & $\begin{array}{c}2 \text { Days } \\
\text { Serum-depletion }\end{array}$ & $\begin{array}{c}\text { PALA } \\
\text { LD }_{50}(\mu \mathrm{M})\end{array}$ & $\begin{array}{c}\text { PALA } \\
\text { Colonies }\end{array}$ & $\begin{array}{l}\text { CAD gene Amplification } \\
\text { Frequency at } 6 \times L_{50}\end{array}$ \\
\hline Balb & 17.5 & + & - & $5 \mu \mathrm{M}$ & $0 / 1 \times 10^{7}$ & $\mathrm{ND}\left(<1 \times 10^{7}\right)$ \\
\hline Balb & 17.5 & + & + & $5 \mu \mathrm{M}$ & $0 / 1 \times 10^{7}$ & $\operatorname{ND}\left(<1 \times 10^{7}\right)$ \\
\hline Ki-Balb & 25 & - & - & $12 \mu \mathrm{M}$ & $17 / 1 \times 10^{6}$ & $1 \times 10^{5} \pm 4 \times 10^{4}$ \\
\hline Ki-Balb & 25 & - & + & $12 \mu \mathrm{M}$ & $0 / 1 \times 10^{7}$ & \\
\hline
\end{tabular}

The frequencies of PALA resistance were determined as described in the Methods and Materials. PE represents plating efficiency. p53 refers to the expression of wtp53 protein. $L_{50}$ is the concentration of PALA that reduces colony forming ability by $50 \%$. ND indicates that no PALA-resistant colonies were detected 


\section{PALA-induced apoptosis accompanied by loss of PALA-mediated G1 arrest in cells expressing oncogenic Ki-Ras}

Since Ki-Balb cells cannot be arrested in cell cycle by serum-depletion, the effect of PALA on cell cycle progression was determined (Figure 5a). The DNA profiles of the cells were analyzed at day 6 of PALA treatment, and compared with profiles from the same cells cultured under normal growth conditions. The majority of Balb cells accumulated in the G1-phase in the presence of PALA. In contrast, Ki-Balb cells remained distributed throughout the cell cycle, indicating that oncogenic Ras perturbed PALA-induced cell cycle arrest.

The effect of PALA at higher doses on cell viability also differed between these two cell types (Figure 5b). Cell viability in the presence of PALA at $8 \times L_{50}$ was assayed over a 3 week period and was quantitated at 6 -day intervals by trypan blue exclusion. More than $80 \%$ of Balb cells were still viable at the end of 3 weeks, and most of the viable a
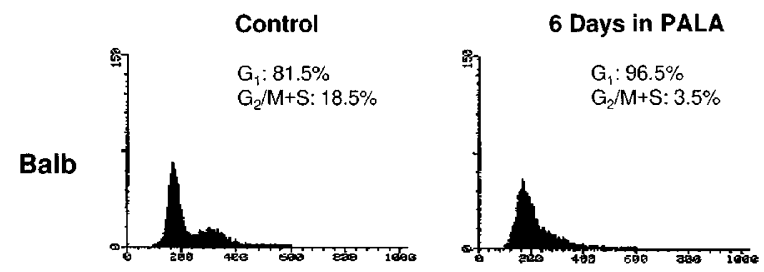

Control
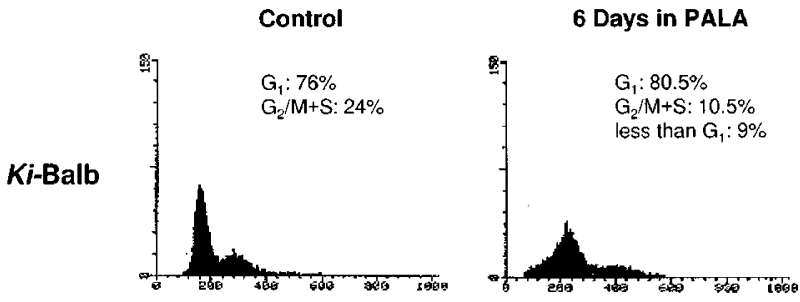

c

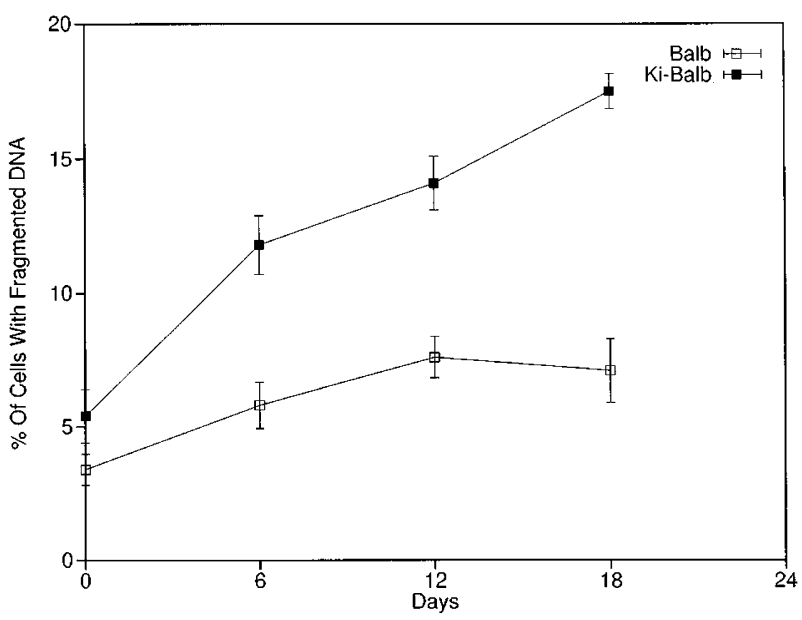

cells remained arrested in G1-phase during this period. In contrast, far fewer Ki-Balb cells survived the $8 \times L^{2} D_{50}$ concentration of PALA, but at the same time, those cells which did survive were able to form colonies in the presence of PALA, demonstrating that they remained in cell cycle. To determine whether the decrease in survival of $K i$-Balb cells during PALA treatment was due to apoptosis, the percentage of the cells with fragmented DNA, a characteristic feature of apoptosis, was measured by staining a portion of the same cells shown in Figure $5 \mathrm{~b}$ with propidium iodide at 6-day intervals, followed by nuclear DNA analysis on a fluorescence-activated flow cytometer (Figure $5 \mathrm{c}$ ). The percentage of $K i$-Balb cells with fragmented DNA increased, and persisted, at a level of more than $10 \%$ for the 18 -day treatment period, while in control Balb cells no significant increase in DNA fragmentation was observed. This suggested that loss of the viability of Ki-Balb cells during PALA selection was due to apoptosis. Taken together with the data from Figure $5 \mathrm{a}$, it also suggested that this PALA-mediated apoptosis in the

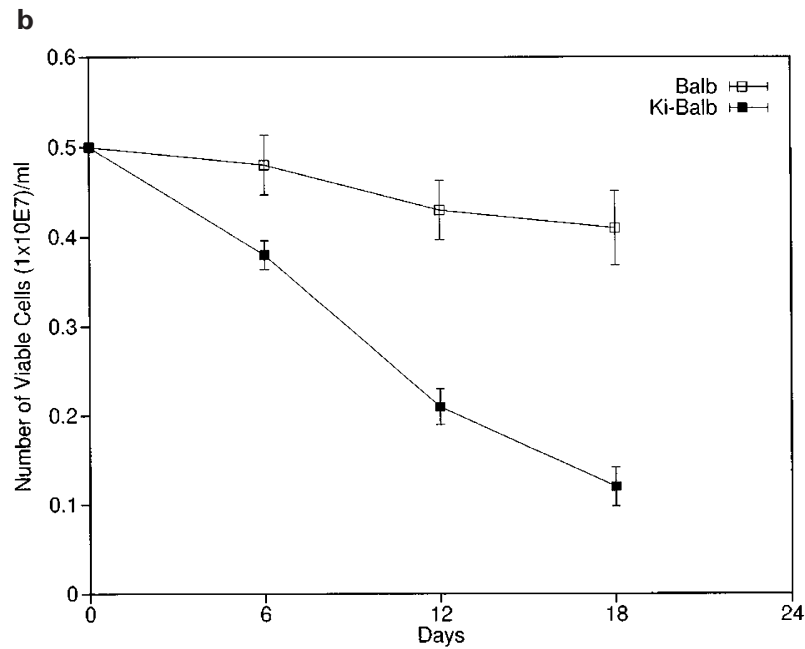

Figure 5 Loss of growth arrest and of viability mediated by PALA in Ki-Rasexpressing cells. (a) Flow cytometric DNA profiles of Balb and Ki-Balb cells after 6 days of PALA selection, as compared to cells grown without PALA selection. The percentages of cells in $\mathrm{G} 1, \mathrm{~S}$, and G2/M are indicated. (b) Five replicate plates of Balb and Ki-Balb cells were cultured in a concentration of $8 \times \mathrm{LD}_{50}$ PALA ( $40 \mu \mathrm{M}$ for Balb cells and $120 \mu \mathrm{M}$ for Ki-Balb cells), and viable cells were enumerated at 6-day intervals for 18 days. (c) Nuclear DNA fragmentation in the same cell lines in the presence of PALA used at the concentrations described in $\mathbf{b}$, was analyzed at 6-day intervals for 18 days 


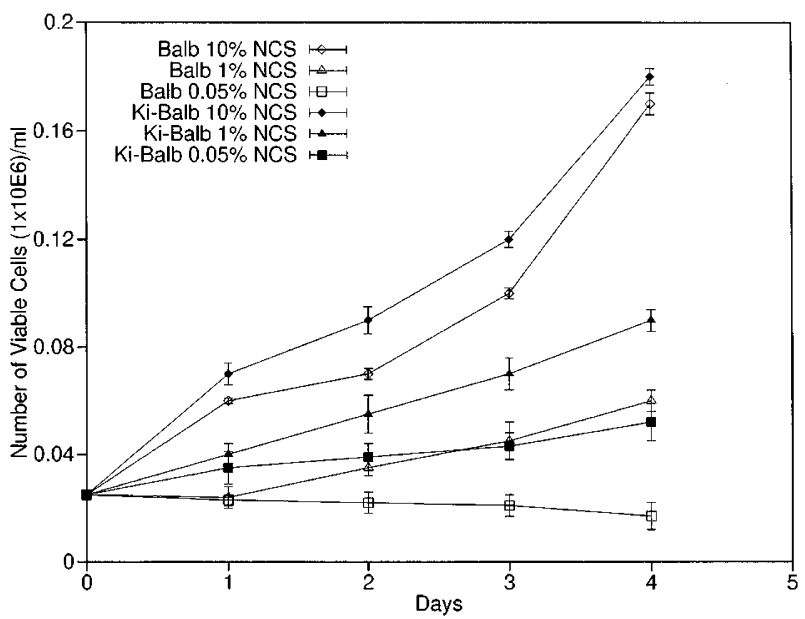

b

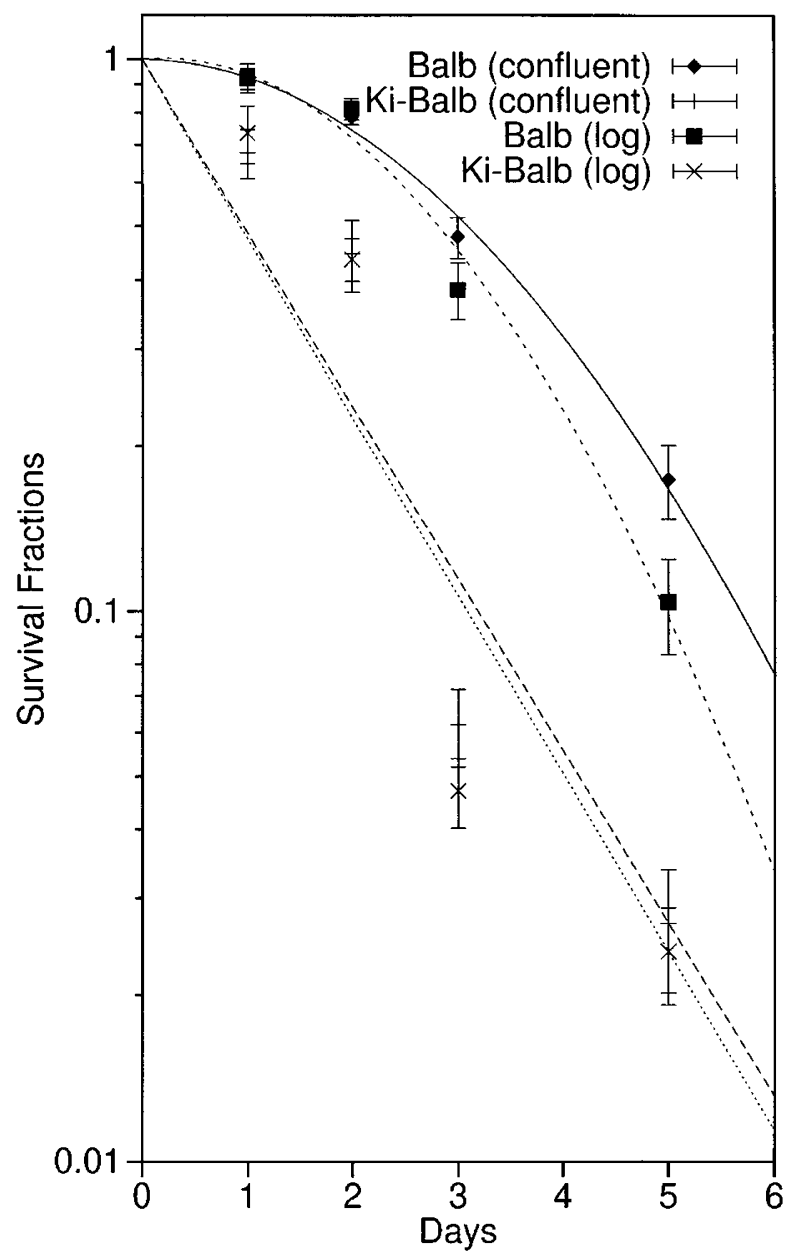

Figure 6 Cell kinetics with or without serum withdrawal and hypothetical extrapolated survival curves for Balb and $K i$-Balb cells after various times of serum-starvation in a clonogenic assay. (a) Five replicate wells of Balb or KiBalb cells were cultured in medium containing various concentrations of newborn calf serum as indicated. Viable cells were enumerated at daily intervals for 4 consecutive days. Error bars indicate standard errors. (b) Balb and Ki-Balb cells cultured under log growth or confluent conditions were subjected to different time periods of serum-starvation. Afterwards, clonogenic assays were performed. The fraction of surviving cells is plotted on a presence of oncogenic Ras, like the formation of PALAresistant colonies, may be dependent upon Ras-induced transit through the cell cycle beyond G1. However, this program of cell death was simultaneously accompanied by the generation of PALA-resistant colonies, which indicates that the genetic instability caused by oncogenic Ras may simultaneously contribute to two opposing biological processes: gene amplification conferring resistance to environmental stresses and enhanced sensitivity to apoptosis.

\section{Reduction of clonogenicity in cells expressing oncogenic Ki-Ras following serum-depletion}

Constitutive expression of myc results in rapid apoptosis after withdrawal of serum (Evan et al, 1992). To explore the effects of activated Ras under the same conditions, control Balb cells and $K i$-Balb cells were cultured in medium containing various concentrations of newborn calf serum and the viable cells were enumerated at daily intervals over 4 consecutive days (Figure 6a). The growth rate of Balb cells was reduced with decreasing concentrations of serum. The number of Balb cells remained approximately the same (no growth) in medium containing $0.05 \%$ serum over the 4 -day interval. The cell growth kinetics of $\mathrm{Ki}$-Balb cells were moderately elevated in medium containing $10 \%$ serum in comparison with Balb cells. At the lower concentrations of serum, the growth rate of $\mathrm{Ki}$ Balb cells was relatively decreased, but the cells continued to proliferate, even at $0.05 \%$ serum. This confirmed previous observations that constitutively-activated Ras, to some extent, may still provide signals for cell cycle progression and production of viable daughter cells under conditions of serum-starvation. Cell viability was also determined by DNA fragmentation analysis (data not shown). There was no obvious increase in the percentage of cells with fragmented DNA in either Balb or Ki-Balb cells over the four days of serum-starvation.

Since the cells expressing oncogenic Ki-Ras did not die during the 4-day period of serum-starvation, we next assessed whether there was an impact of prolonged serum-starvation on the longevity/propagation capability, or on the repair ability, of these cells with their propensity for genomic instability due to the presence of activated Ras. Colony formation assays were conducted following various periods of incubation in medium depleted of serum. Balb cells and $K i$-Balb cells, initially under either confluent or log growth conditions, were cultured in medium containing $0.05 \%$ of serum for various time intervals as indicated, and the viable cells were subsequently replated for clonogenicity assays. For each experiment, parallel control dishes were set up for determination of the plating efficiency (PE). The empirical survival curve model $(\alpha / \beta$ model), which has been widely used in radiobiology to access cell sensitivity to radiation or the capacity to repair radiation-induced damage (Chen and Geard, 1990; Fisher,

logarithmic scale against duration of serum-starvation on a linear scale. The coefficients $\alpha$ and $\beta$ relate to the initial slope and final slope, respectively 
1994; Hallberg et al, 1994; Hall, 1994), was employed to analyze the results of this assay (Figure 6b). $\alpha$ represents the linear component of the slope and $\beta$ is the final nonlinear component of the slope of the cell survival curve in response to various inducers of cellular damage. The survival curves for Balb and Ki-Balb cells are presented as duration of serum-depletion plotted on a linear scale with surviving fraction on a logarithmic scale. The survival curves of Ki-Balb cells under both conditions (whether initially confluent or in 'log phase'), were approximately linear with similar $\alpha$ components. The lines for the Balb cells were nonlinear under both confluent and 'log' conditions. In analyzing such plots in the assessment of survival after radiation exposure, a non-linear survival curve, like that seen for the Balb cells, suggests the need for multiple 'hits' to induce cell death; in contrast, a linear curve, as seen for the Ki-Balb cells, implies the need for only a single 'hit'. One interpretation of these results could be that the presence of activated Ras might provide the first hit, either through accumulation of genetic damage or disruption of repair capability. The latter part of the slope of the curve (the $\beta$ component) from 'log phase' Balb cells became steeper than the $\beta$ component from the confluent Balb cells, which may reflect that these normal cells may have differing sensitivities to persistent serum-starvation in different phases of the cell cycle. Under confluent conditions, the majority of Balb cells resided in the G0/ G1-phase of the cell cycle as a result of contact inhibition. Cells in G1-phase may be less sensitive to, or more efficient in repair of, the damage or stress caused by extended withdrawal of growth factors. Since transformed $K i$-Balb cells lose contact inhibition as well as their $\mathrm{G} 1$ cell cycle checkpoint, the effect of prior confluence or log growth conditions may not alter the intrinsic sensitivity of these cells to serum-depletion.

\section{Loss of PALA-resistant colony formation potential in the presence of activated Ki-Ras following serum-starvation}

The clonogenicity experiments detailed above suggested that the loss of longevity or propagation ability of Ki-Balb cells following persistent serum-starvation may be due to the accumulation of genetic errors or the inability to repair cellular damage. To determine if $K i$-Balb cells retained the ability to generate PALA-resistant colonies following serum-starvation, Balb and $K i$-Balb cells were incubated in medium with $0.05 \%$ of newborn calf serum for 2 days, and then cultured in normal growth medium in the presence of PALA for colony-forming assays. The 2 day period of serum-starvation was determined from Figure 6, which showed that the majority of the cells were viable after this interval of serum-starvation, and that $30-40 \%$ of seeded $\mathrm{Ki}$-Balb cells would still form colonies. No PALAresistant colonies arose from $1 \times 10^{8}$ plated Balb cells after 2 days of prior serum starvation (Table 1 ). Ki-Balb cells also failed to generate any PALA-resistant colonies when seeded in the same numbers as the Balb cells.

The effect of PALA on induction of apoptosis were examined using this combination of serum-starvation and PALA treatment. Cells were cultured in medium containing
$0.05 \%$ serum for 2 days, and then returned to normal growth conditions in the presence of PALA at $8 \times L_{50}$ for 6 days. Subsequently, cellular DNA fragmentation analysis was conducted (Figure 7). The percentage Balb cells exhibiting DNA fragmentation after the combination treatment was slightly, but not significantly, higher than in Balb cells growing under normal conditions (4.2 vs. $3.5 \%$ ). However, the majority of the Balb cells remained viable and in a state of growth arrest (data not shown). Prior serum-starvation treatment increased the percentage of PALA-mediated DNA fragmentation in Ki-Balb cells (to about $18.5 \%$ at day 6 ) in comparison with the cells treated with PALA without prior serum-starvation (about 11\%). Overall, these results imply that the $C A D$ gene amplification induced by (or permitted by) the presence of the Ki-ras oncogene was suppressed by prior serum-starvation of the cells.

\section{Discussion}

The development and progression of cancer is a multistep process. Molecular and cytogenetic examinations have revealed that the progressive stages of tumorigenesis are driven by stochastic accumulation of genetic and epigenetic changes in tumor cells. Loss of the function of certain tumor suppressors can eliminate a cell cycle checkpoint (G1/S) and enhance the frequency of genetic errors through genomic instability. The studies presented here demonstrate that the susceptibility to restructuring of the transformed cell genome by oncogenic Ras, through the disruption of the expression of tumor suppressor p53, not only confers some activities predisposing to cancer cell development, but also may render the same cells more susceptible to apoptotic processes. We also demonstrate that such cells with such unstable genomes have an increased tendency to accumulate lethal genetic errors, or may be unable to repair cellular

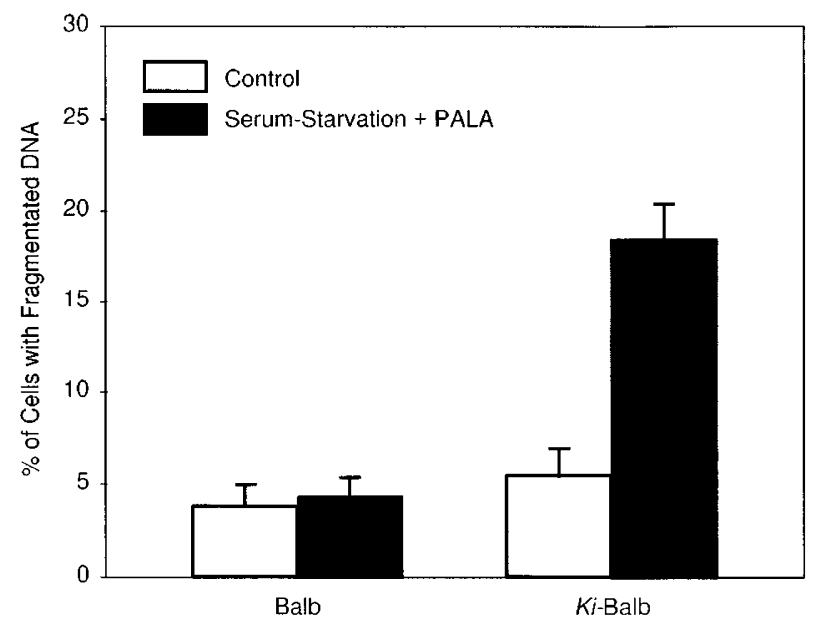

Figure 7 PALA-mediated DNA fragmentation following serum-starvation. The cells were cultured in the medium containing $0.05 \%$ of serum for 2 days, and subsequently cultured under normal growth conditions in the presence of $8 \times \mathrm{LD}_{50}$ of PALA for 6 days. The DNA fragmentation of Balb and Ki-Balb cells were examined by flow cytometry. Error bars represent the standard error over five independent experiments 
damage, when they are forced to enter the cell cycle aberrantly or prematurely. Both immediate apoptosis and loss of longevity or propagation ability are the results of this process.

The differential ability of Balb cells and Ki-Balb cells to form colonies in response to persistent serum-deprivation or to PALA-exposure raised the possibility that activated Ras may utilize a common bi-functional cellular component in directing the cells to undergo apoptosis or tumorigenesis. The tumor suppressor p53 has pleiotropic functions, including control of genomic plasticity and integrity, as well as modulation of repair pathways. Cells with impaired p53 have been shown to be genetically unstable, owing to loss of cell cycle checkpoint control and accumulation of misrepair events (Fornace et al, 1989; Livingstone et al, 1992; Yin et al, 1992; Carder et al, 1993; Schaefer et al, 1993; Lee et al, 1994; Bouffler et al, 1995; Donehower et al, 1995). Analysis of wt-p53 protein expression in the presence of oncogenic Ras showed that such cells have reduced levels of this tumor-suppressor protein in both nuclear-free cell lysate and nuclear fractions. This disruption of the expression of wt-p 53 protein by activated Ras was negatively-correlated with the capacity for PALAmediated cell cycle arrest, and positively-correlated with an increased frequency of PALA-selected CAD gene amplification and an increased susceptibility to PALA-induced apoptosis. Mutation or inactivation in genes with diverse functions such as p53 may contribute to abnormal chromosomal rearrangements in cells, including gene amplification. Genes encoding protein that participate in DNA replication or repair can also confer genomic instability when mutated. Amplified gene structures may be formed in both normal and tumor-prone cells, but can be repaired in normal cells (Tlsty, et al, 1989; Tlsty, 1990). For instance, transfection of wt-p53 into the fibroblasts from LiFraumeni syndrome patients lacking wt-p53 expression will restore $\mathrm{G} 1$ cell cycle arrest and inhibit $C A D$ gene amplification (Livingstone et al, 1992; Yin et al, 1992). The data presented herein demonstrate that in cells expressing oncogenic Ras, exposure to PALA efficiently induced programmed cell death, and this PALA-mediated susceptibility to apoptosis was also associated with the capacity to generate PALA-resistant colonies. One possible interpretation of this observed correlation between genetic instability and susceptibility of apoptosis induced by PALA in the presence of activated Ras could be that the loss of the PALA-mediated gating mechanism at the G1/S checkpoint, perhaps together with a defect in proof-reading mechanisms, may initiate replication-associated chromosome breakage and the generation of acentric fragments containing target genes, leading to a gene amplification process in a small proportion of the Ki-Balb cells. For the majority of the Ki-Balb cell population, however, the increased apoptotic activity of PALA mediated by oncogenic Ras may be secondary to its known ability to reduce the intracellular pools of nucleotides, such as dTTP, dCTP, dGTP and UTP (Moyer et al, 1982). Premature transition through S-phase under limited concentrations of dTTP alone is sufficient to cause apoptosis (Koyama et al, 1982; Ayusawa et al, 1983).
Activated Ras does not promote the apoptotic process during short-term serum-starvation (Chen and Faller, 1995). Here, our data further demonstrated that during 4 days of serum depletion, oncogenic Ki-Ras continues to act as a mitogenic signal transducer to drive $K i$-Balb cells to proliferate, although the cell doubling time was modestly extended in the absence of serum. However, the colony formation assay showed that the ability of $K i$-Balb cells to generate colonies was dramatically reduced with persistent serum-starvation. Interestingly, the survival curves of Balb and $\mathrm{Ki}$-Balb cells in response to different time periods of serum-depletion fit the prominent model describing cellular sensitivity to radiation, in which an increasing slope of the curve correlates with enhanced radio-sensitivity of cells perhaps through lack of ability to repair DNA breaks caused by radiation. Therefore, without proper cell cycle checkpoint surveillance as part of genetic control, cell cycle progression under the condition of persistent serum-starvation may cause cellular damage or stress, and cells deficient in repair processes would be sensitive to this stress, leading to loss of longevity or propagation ability or apoptosis. The discrepancy found between the assays of the cell growth kinetics during serum-starvation and the colony formation after serum-depletion in $K i$-Balb cells may thus reflect two different functions of oncogenic ras in two different 'environments'. During conditions of low-serum concentration, the mitogenic function of oncogenic Ras may compensate for certain growth factors in the serum to promote cell proliferation within certain time periods; but at the same time, however, without the control conferred by the G1 checkpoint and with impaired repair machinery (such as GADD45-involved repair processes), oncogenic Ras may accelerate the accumulation of lethal genetic errors which may affect the longevity of the cells. This cumulative genetic damage may then be revealed by the clonogenicity assay. In a clonogenicity assay after persistent serum-depletion, cells must be able to repair or recover from the preceding damage or stress to form colonies. In the presence of oncogenic Ras, however, such repair machinery may become inefficient or inaccurate with increasing time periods of serum-starvation.

Both serum-starvation and PALA-exposure can arrest normal Balb cells in G1 of the cell cycle, but Balb cells expressing activated Ras do not arrest under either condition. The differential ability of $K i$-Balb cells to form colonies following these two stresses may derive from a common, unstable genetic background, but may be due to two different mechanisms. Inability of $K i$-Balb cells to propagate following persistent serum-starvation may indicate a defect in the processes of repair of cellular damage. Yet, in the presence of PALA selection, a small fraction of the Ki-Balb cells are able to form PALA-resistant colonies because they were permissive for $C A D$ gene amplification, indicating impaired recombination machinery or processes during DNA replication. The combination of serum-starvation plus PALA-exposure in cells expressing oncogenic Ras, however, appeared to synergize the apoptotic process. The cell cycle transit through the G1 checkpoint enforced by oncogenic Ras in the absence of certain growth factors (serum) may inhibit or damage the 
genes which may subsequently regulate the initiation of the breakage-fusion-bridge cycle triggered by PALA to facilitate the CAD gene amplification and the formation of PALAresistant colonies. However, it is also reasonable to postulate that oncogenic Ras may interfere with tumor suppressors, such as p53, and further lead cells to undergo numerous genomic alterations by affecting different genetic mechanisms. A genome so changed has the potential not only for tumorigenesis but also for increased susceptibility to cell death, depending upon the circumstances.

The functions of oncogenic Ras, as a pro- or antiproliferative effector, are the subject of some controversy. Oncogenic Ras has been demonstrated to cause proliferative arrest and differentiation in two rodent cell lines, rat pheochromocytoma $\mathrm{PC} 12$ cells and rat Schwann cells (Ridley et al, 1988; Bar-Sagi and Feramisco, 1985). A recent report has documented that expression of oncogenic $H$-rasV12 in either primary human diploid fibroblasts (IMR90) or primary mouse embryo fibroblasts (MEFs) results in G1 arrest, and such cell progression arrest is accompanied by accumulation of p53 and p16 (Serrano et al, 1997). Conversely, inactivation of tumor suppressors are the most prevalent mutations in some human tumors accompanying oncogenic mutations of the ras gene (Hick et al, 1991; Lu et al, 1992; Tanaka et al, 1994; Weinberg, 1995; Serrano et al, 1996; Hollstein et al, 1996). This discrepancy of oncogenic Ras actions on regulation of $\mathrm{G} 1$ arrest of cell cycle may be cell-type specific, or due to particular steps in tumorigenic development, or to ectopic expression of the oncogene and its subsequent functions, or even to the duration of expression of oncogenic Ras. The cells employed in this investigation are early passage mouse Balb/c-3T3 fibroblasts. These cells still possess many properties of primary cells, such as contact inhibition of cell division, growth at a high dilution, and lack of $C A D$ gene amplification, but are more sensitive to transformation than many primary cell cultures. It is possible that, in the course of establishing Balb cells in culture, some, as yet unknown, intrinsic mutations have occurred which may cooperate with oncogenes, including ras, to disrupt the G1/S cell cycle checkpoint and allow full transformation. It is noteworthy, however, that we have observed similar effects of oncogenic Ras when it is introduced into a human $T$ lymphoblastoid line or into primary human endothelial cells (unpublished).

The present findings may begin to establish connections among disruption of p53, gene amplification, tumorigenesis and susceptibility to apoptosis in the presence of oncogenic Ras. These results are consistent with a model encompassing the dual functions of growth-related genes, such as myc and ras (Evan et al, 1992; Harrington, et al. 1994; Gulbins et al, 1995). Independent of the transformation process, we have shown that cell expressing oncogenic or transiently but inappropriately-activated Ras become more vulnerable to certain environmental changes, such as modulation of PKC activity (Chen and Faller, 1995; Chen, et al, 1998). Under such conditions, the progression of the cells towards two distinct and opposite biological processes, proliferation and apoptosis, is determined by both intrinsic biological or genetic status (e.g. alterations in tumor suppressors) and exogenous inputs (e.g. modulation of enzyme levels). These findings are consistent with a model encompassing the dual functions of proto-oncogene products such as Myc and Ras. Signals for proliferation in normal cells, mediated in part by Ras and Myc, may actively and appropriately suppress the apoptotic process. Under certain conditions, Ras and Myc probably also activate apoptotic pathways to provide a control against unlimited growth. Thus, the same cellular machinery may operate or regulate these two linked processes of cell proliferation and apoptosis. In oncogenic transformation, the signals for proliferation are enhanced by protooncogenes, and the conflict between cell growth and apoptosis may be also intensified. The ability to induce a clash of these two processes by manipulation of the cellular environment may provide a new and promising approach to oncogene-directed cancer therapy.

\section{Materials and Methods}

\section{Cell culture and cell lines}

Mouse fibroblasts, Balb/c-3T3, clone A31 initially developed from 14day-old Balb/c mouse embryos, were obtained from the American Type Culture Collection (Rockville, MD, USA). The Balb cells were cultured for one or two passages after purchase and aliquoted into freezing vials. For each experiment, freshly-thawed cells were used, which possessed primary cell-like, non-tumorigenic and contactinhibited characteristics. Retroviral vector stocks containing $v$-Ki-ras or c-myc cDNAs were derived from cells transfected with cloned vectors as previously described (Zullo and Faller, 1988). After infection, transfectants were assayed for constitutive expression of ras or myc mRNAs by Northern blot analysis and proteins by immunoblot analysis. Subsequently, cells were maintained in Dulbecco Modified Eagle medium (DME) supplemented with $10 \%$ heat-inactivated newborn calf serum (Hazelton Research Products, Inc., Lenexa, KA, USA), $2 \mathrm{mM} \mathrm{L-glutamine,} 100 \mathrm{U}$ penicillin per $\mathrm{ml}, 100 \mu \mathrm{g}$ streptomycin per $\mathrm{ml}$, and geneticin or hygromycin selection where appropriate. For cell growth kinetic assays, cells (at $0.25 \times 10^{6}$ cells $/ \mathrm{ml}$ ) were incubated in medium containing different percentages of newborn calf serum, and the number of viable cells were determined daily by trypan blue exclusion.

\section{Cell viability assay}

Cells were cultured in medium containing different concentrations of newborn calf serum or PALA for the time periods as indicated in the figures. Viable cells were enumerated at daily intervals using trypan blue exclusion.

\section{DNA content and cell cycle distribution analysis}

After culture in medium containing 10 or $0.05 \%$ of newborn calf serum for $48 \mathrm{~h}$, cells $\left(1 \times 10^{6}\right)$ were washed with $1 \times$ PBS twice, fixed with $70 \%$ ethanol, and subsequently resuspended in $1 \mathrm{ml}$ of $1 \% \mathrm{Na}$ citrate, $0.1 \%$ Triton $\mathrm{X}-100$ and $50 \mu \mathrm{g} / \mathrm{ml}$ of propidium iodide. DNA profile analysis was performed with a FACScan (Becton Dickenson, Mountain View, CA, USA). The data analysis and display were performed using the Cell-Fit software program (Becton Dickenson, Mountain View, CA, USA). Cell-Fit provides data from the flow cytometer for real-time 
statistical analysis, computed at $1 \mathrm{~s}$ intervals, and also discriminates doublets or adjacent particles. The same procedure of the DNA profile analysis was conducted for the PALA selection procedures, wherein the cells were grown in medium with or without PALA at $8 \times L_{50}$ for 6 days, prior to the analysis.

\section{Cell survival assay}

A cell survival assay was used to examine the ability of single cell to form colonies after various periods of serum-starvation. After culturing cells in medium containing either 10 or $0.05 \%$ newborn calf serum for various time periods as indicated, Balb and Ki-Balb cells were trypsinized, and re-plated in $100 \mathrm{~mm}$ dishes at suitable dilutions. The incubations were carried out at $37^{\circ} \mathrm{C}$ for 14 days, after which the colonies obtained were fixed, stained, and counted. The plating efficiency for each cell line was established by determining the number of cells required to yield 50 colonies per dish under normal growth conditions.

\section{Immunoprecipitation and Western blot analysis}

After growth in the medium containing 10 or $0.05 \%$ newborn calf serum for $48 \mathrm{~h}$, cells $\left(20 \times 10^{6}\right)$, were trypsinized and washed with $1 \times \mathrm{PBS}$ three times. The cells were resuspended in lysis buffer containing $20 \mathrm{mM}$ Tris- $\mathrm{HCl}$ (p H 7.5), 2 mM EDTA, 5 mM EGTA [ethylene glycolbis ( $\zeta$-aminoethyl ether)- $\mathrm{N}, \mathrm{N}, \mathrm{N}^{\prime}, \mathrm{N}^{\prime}$-tetraacetic acid], $10 \mathrm{mM} \beta$-mercaptoethanol, and $10 \eta \mathrm{g}$ of leupeptin and aprotinin per $\mathrm{ml}$, and passed through a 22-gauge needle several times. The lysates were centrifuged at $280 \times \mathrm{g}$ for $10 \mathrm{~min}$ at $4^{\circ} \mathrm{C}$. The supernatants were collected as nuclear-free cell lysates and the pellets as nuclei. Subsequently, nuclei were resuspended in $50 \mu \mathrm{l}$ of nuclear buffer containing $20 \mathrm{mM}$ HEPES (pH 7.9), $420 \mathrm{mM} \mathrm{NaCl}, 1.5 \mathrm{mM} \mathrm{MgCl}$, $0.2 \mathrm{mM}$ EDTA, $0.5 \mathrm{mM}$ DTT, $0.2 \mathrm{mM}$ phenylmethylsulfonyl fluoride. The protein concentrations in the nuclear-free cell lysates or the nuclear extracts were normalized. Equal amounts of total protein from different cell fractions were immunoprecipitated by using anti-mousep53 antibody (Oncogene Science, Uniondale, NY, USA), and subsequently immunoblotted with the same antibody. The immunoblots were developed with an anti-mouse Ig alkaline phosphatase reagent (Oncogene Science).

\section{RNA blot analysis}

Total cellular RNA was isolated by guanidine thiocyanate/phenol RNA extraction, quantified, separated by electrophoresis on formaldehydeagarose gels, and transferred to nitrocellulose (Costar, Cambridge, MA, USA). Hybridization and high stringency wash were performed as previously described (Faller et al, 1994). [ $\left.{ }^{32} \mathrm{P}\right]$-labeled DNA probes were made by the random oligonucleotide primer method (Feinberg and Volgelstein, 1983). The GADD45 probe was a $1.2 \mathrm{~kb}$ Kpnl to Sacl fragment of hamster GADD45 (generously provided by Dr. A. Fornace). The MDM-2 probe was a $1.3 \mathrm{~kb} E c o R I$ fragment of murine MDM-2 (generously provided by Dr. A. Fornace).

\section{PALA selection}

Balb and Ki-Balb cells were grown in the presence of various concentrations of PALA, a drug that specifically inhibits the aspartate transcarbamylase activity of the multifunctional CAD enzyme and selects for cells with amplified copies of $C A D$ gene (obtained from the Drug Synthesis Branch, Division of Cancer Treatment, National Cancer Institute). Subsequently, the concentration of PALA that inhibited colony-forming ability by $50 \%\left(L_{50}\right)$ was determined for each cell line. Cells were selected to resist to PALA (at $6 \times \mathrm{LD}_{50}$ ) and be able to grow to form colonies in 4-5 weeks. Frequency of $C A D$ gene amplification was expressed as the number of colonies formed in $6 \times \mathrm{LD}_{50}$ of PALA relative to the number of colonies formed without PALA.

\section{Southern blot analysis}

DNA was prepared from the colonies of Ki-Balb cells after PALA selection as described above as well as from normal Balb cells. The genomic DNA was digested with restriction endonucleases, precipitated with $\mathrm{EtOH}$, and subsequently dissolved in TE. Equal amounts of digested genomic DNA was loaded in each lane of the agarose gel, fractionated by electrophoresis, and transferred to nitrocellulose. The mouse $C A D$ probe was generated by PCR as a $300 \mathrm{bp}$ of DNA fragment using primers (5'-GAGCGAGATACACGCACGTTGCA and 3'-CCTGAATGAACTTGGAGATGACTA), radiolabeled by the random primer method, and hybridized to the nitrocellulose filters.

\section{Acknowledgements}

We thank Dr. A. Fornace for the generous gift of molecular probes and vectors. This work was supported by a research grant from the National Cancer Institute (CA50459). C.Y.C. is supported by a Cardiovascular Biology Training Grant from NHLBI.

\section{References}

Arber N, Sutter T, Miyake M, Kahn SM, Venkatraj VS, Sobrino A, Warburton D, Holt PR and Weinstein BI (1996) Increased expression of cyclin D1 and the Rb tumor suppressor gene in c-k-ras transformed rat enterocytes. Oncogene 12: 19031908

Askew DS, Ashmun RA, Simmons BC, and Cleveland JL (1991) Constitutive c-myc expression in an IL-3-dependent myeloid cell line suppresses cell cycle arrest and accelerates apoptosis. Oncogene 6: 1915-1922

Avruch J, Zhang X and Kyriakis JM (1994) Raf meets Ras: completing the framework of a signal transduction pathway. Trends in Biochem Sci. 19: $279-$ 283

Ayusawa D, Shimizu K, Koyama H, Takeishi K and Seno T (1983) Accumulation of DNA strand breaks during thymineless death in thymidylate synthase-negative mutants of mouse FM3A cells. J. Biol. Chem. 258: 12448-12454

Barbacid M (1987) ras genes. Annual Review of Biochemistry pp.779-827

Bar-Sagi D and Feramisco JR (1985) Microinjection of the ras oncogene protein into PC12 cell induces morphological differentiation. Cell 42: $841-848$

Bouffler SD, Kemp CJ, Balman A and Cox K (1995) Spontaneous and ionizing radiation-induced chromosomal abnormalities in p53-deficient mice. Cancer Res. 55: 3883-3889

Buday L and Downward J (1993) Epidermal growth factor regulates the exchange rate of guanine nucleotides on p21Ras in fibroblasts. Mol. Cell. Biol. 13: 19031910

Bourne HR, Wrischnik L and Kenyon C (1990) Ras proteins. Some signal developments. Nature 348: 678-679

Cahilly-Snyder L, Yang-Feng T, Fancke U and George DL (1987) Molecular analysis and chromosomal mapping of amplified genes isolated from a transformed mouse 3T3 cell line. Somat. Cell. Mol. Genet. 13: 235-244

Carder P, Wyllie AH, Purdie CA, Morris RG, White S, Piris J and Bird CC (1993) Stabilized p53 facilitates aneuploid clonal divergence in colorectal cancer. Oncogene 5: 1397-1401

Chen C-Y and Geard CR (1990) Relationship between cell survival and the incidence of micronuclei after low and high dose rate $\gamma$-irradiation of normal human fibroblasts. Radiat. Res. 124: 125-132

Chen C-Y and Faller DV (1995) Direction of p21Ras-generated signals cell growth or apoptosis is determined by protein kinase $\mathrm{C}$ and $\mathrm{Bcl}-2$. Oncogene 11: 1487 1498 
Chen C-Y and FallerDV (1996) Phosphorylation of Bcl-2 protein and association with p21Ras in Ras-induced apoptosis. J. Biol. Chem. 271: 2376-2379

Chen C-Y, Liou J, Forman LW, and Faller DV (1998) Differential regulation of discrete apoptotic pathways by Ras. J. Biol. Chem., in press

Chin K-V, Ueda K, Pastan I and Gottesman MM (1992) Modulation of activity of the promoter of the human MDRI gene by Ras and p53. Science 255: 459-462

Denko NC, Giaccia AJ, Stringer JR and Stambrook PJ (1994) The human Ha-ras oncogene induces genomic instability in murine fibroblasts within one cell cycle. Proc. Natl. Acad. Sci. USA 91: 5124-5128

de Vries JE, Kornips FHAC, Marx P, Bosman FT, Geraedts JPM and Kate JT (1993) Transfected c-Ha-ras oncogene enhances karyotypic instability and integrates predominantly in aberrant chromosomes. Cancer Genet. Gyotgenet. 65: 35-43

Donehower LA, Godley LA, Aldaz CM, Pyle R, Shi Y-P, Pinkel D, Gray J, Bradley A Medina D and Varmus HE (1995) Deficiency of p53 accelerates mammary tumorigenesis in wnt- 1 transgenic mice and promotes chromosomal instability. Genes. Dev. 9: 882-895

Downward J, Graves JD, Warne PH, Rayter S and Cantrell DA (1990) Stimulation of p21Ras upon T-cell activation. Nature 346: 719-723

Eliyahu D, Michalovitz D, Eliyahu S, Pinhasi-Kimhi O and Oren M (1989) Wild-type p53 can inhibit oncogene-mediated focus formation. Proc. Natl. Acad. Sci. USA 86: $8763-8767$

Evan GI, Wyllie AH, Gilbert CS, Littlewood TK, Land H, Brooks M, Waters CM, Penn LZ and Hancock DC (1992) Induction of apoptosis in fibroblasts by c-myc protein. Cell 69: 119-128

Fakharzadeh SS, Trusko SP and George DL (1991) Tumorigenic potential associated with enhanced expression of a gene that is amplified in a mouse tumor cell line. EMBO J. 10: 1565-1569

Faller DV, Mundschau LJ, Forman LW and Quinones MA (1994) v-mos suppresses platelet-derived growth factor (PDGF) type-beta receptor autophosphorylation and inhibits PDGF-BB-mediated signal transduction. J. Biol. Chem. 269:5022 5029.

Feinberg AP and Volgelstein B (1983) A technique for radiolabeling DNA restriction endonuclease fragments to high specific activity. Anal. Biochem. 132: 6-13

Filmus J, Robles AI, Shi W, Wong MJ, Colombo LL and Conti CJ (1994) Induction of cyclin D1 overexpression by activated ras. Oncogene 9: 3629-3633

Finlay CA, Hinds PW and Levine AJ (1989) The p53 proto-oncogene can act as a suppressor of transformation. Cell 57: 1083-1093

Fisher DE (1994) Apoptosis in cancer therapy: crossing the threshold. Cell 78: 539 542

Fornace AJ, Alamo I and Hollander MC (1988) DNA damage-inducible transcripts in mammalian cells. Proc. Natl. Acad. Sci. USA 85: 8800-8804

Fornace AJ, Nebert D, Hollander MC, Papathanasiou M, Fargnoli J and Holbrook N (1989) Mammaliam genes coordinately regulated by growth arrest signals and DNA-damaging agents. Mol. Cell. Biol. 9: 4196-4203

Gulbins E, Bissonnette R, Mahoubi A, Martin S, Nishioka W, Brunner T, Baier G Baier-Bitterlich G, Byrd C, Lang F, Kolesnick R and Green D (1995) Fas-induced apoptosis is mediated via a ceramide-initiated Ras signaling pathway. Immunity 2: $341-351$

Hall EJ (1994) Radiobiology for the radiologist. Philadelphia: J. B. Lippincott company pp. $245-256$

Hallberg B, Rayter SI and Downward J (1994) Interaction of Ras and Raf in intact mammalian cells upon extracellular stimulation. J. Biol. Chem. 269: 39133916

Harrington EA, Bennett MR, Fanidi A and Evan Gl (1994) c-myc-induced apoptosis in fibroblasts is inhibited by specific cytokines. EMBO J. 13: 3286-3295

Harris CC and Hollstein M (1993) Clinical implication of the p53 tumor suppressor gene. N. Engl. J. Med. 329: 1318-1327

Hartwell LH and Weinert TA (1989) Checkpoints: controls that ensure the order of cell cycle events. Science 246: 629-634

Hartwell LH (1992) Defects in a cell cycle checkpoint may be responsible for the genomic instability of cancer cells. Cell 71: 543-546

Hartwell LH and Kastan MB (1994) Cell cycle control and cancer. Science 266 $1821-1828$

Hattori S, Fukuda M, Yamashita T, Nakamura S, Gotoh Y and Hishida E (1992) Activation of mitogen-activated protein kinase and its activator by ras in intact cells and in a cell-free system. J. Biol. Chem. 267: 20436-20351

Hick GG, Egan SE, Greenberg AH and Mowat M (1991) Mutant p53 tumor suppressor alleles release ras-induced cell cycle growth arrest. Mole. Cell. Biol. 11: $1344-1352$
Hirakawa T and Ruley HE (1988) Rescue of cells from ras oncogene-induced growth arrest by a second, complementing, oncogene. Proc. Natl. Acad. Sci. USA 85: $1519-1523$

Hollstein M, Shomer B, Greenblatt M, Soussi T, Hovig E, Montesano Rand Harris CC (1996) Somatic point mutations in the p53 gene of human tumors and cell lines: updated compilation. Nucleic Acids Res. 24: 141-146

Kastan MB, Zhan Q, El-Deiry WS, Carrier F, Jacks T, Walsh WV, Plunkett BS, Vogelstein B and Fornace AJ (1992) A mammalian cell cycle checkpoint pathway utilizing p53 and GADD45 is defective in Ataxia-Telangiectasia. Cell 71:587597

Kelly RE, DeRose ML, Draper BW and Wahl GM (1995) Identification of an origin of bidirectional DNA replication in the ubiquitously expressed mammalian $C A D$ gene. Mol. Cell. Biol. 15: 4136-4148

Khosravi-Far Rand Der CJ (1994) The Ras signal transduction pathway. Cancer and Metastasis Rev. 13:67-89

Koyama H, Ayusawa D, Tsuji M and Seno T (1982) Thymineless death and mutation induction in cultured mouse FM3A cell mutants deficient in thymidylate synthase. Mutat. Res. 105: 433-438

Lee JM, Abrahamson JL, Kandel R, Donehower LA and Bernstein A (1994) Susceptibility to radiation-carcinogenesis and accumulation of chromosomal breakage in p53 deficient mice. Oncogene 9: 3731-3736

Li B-Q, Kaplan D, Kung H-F and Kamata T (1992) Nerve growth factor stimulation of the Ras-guanine nucleotide exchange factor and GAP activities. Science 256: $1456-1459$

Liu J-J, Chao J-R, Jiang M-C, Ng S-Y, Yen JJ and Yen HEY (1995) Ras transformation results in an elevated level of cyclin D1 and acceleration of G1 progression in NIH-3T3 cells. Mol. Cell. Biol. 15: 3654-3663

Livingstone LR, White A, Sprouse J, Livanos E, Jacks T and TIsty TD (1992) Altered cell cycle arrest and gene amplification potential accompany loss of wild-type p53. Cell 70: 923-935

Lovec H, Sewing A, Lucibello FC, Muller R and Moroy T (1994) Oncogenic activity of cyclin D1 revealed through cooperation with Ha-ras: link between cell cycle control and malignant transformation. Oncogene 9: 323-326

Lu X, Park SH, Thompson TC and Lane P (1992) Ras-induced hyperplasia occurs with mutation of $\mathrm{p} 53$, but activated ras and myc together can induce carcinoma without p53 mutation. Cell 70: 153-161

Marshall MS (1993) The effector interactions of p21Ras. Trends Biochem. Sci. 18: $250-254$

Marx J (1994) New link found between p53 and DNA repair. Science 266: 1321 1322

McCormick F (1994) Activators and effectors of ras p21 proteins. Curr. Opin. Genet. Dev. 4: $82-96$

McKenna WG, Bernhard EJ, Markiewicz DA, Rudoltz MS, Maity A and Muschel RJ (1996) Regulation of radiation-induced apoptosis in oncogene-transfected fibroblasts: influence of Ha-ras on the G2 delay. Oncogene 12: 237-245

Medema RH, de Vries-Smits AMM, ven der Zon GCM, Maassen JA and Bos JL (1993) Role of p21Ras in growth factor signal transduction. Mol. Cell. Biol. 13: 155-162

Moll UM, Ostermeyer AG, Haladay R, Winkfield B, Frazier M and Zambetti G (1996) Cytoplasmic sequestration of wild-type p53 protein impairs the $\mathrm{G} 1$ checkpoint after DNA damage. Mol. Cell. Biol. 16: 1126-1137

Momand J, Zambett GP, Olson DC, George D and Levine AJ (1991) The mdm-2 oncogene product transactivation. Cell 69: 1237-1245

Moodie SA, Willumsen BM, Weber MJ and Wolfman A (1993) Complexes of Ras-GTP with Raf-1 and mitogen-activated protein kinase. Science 260: 1658-1661

Moyer JD, Smith PA, Levy EJ and Handschumacher RE (1982) Kintics of N(phosphonacetyl)-L-aspartate and pyrazofurin depletion of pyrimidine ribonucleotide and deoxyribonucleotide pools and their relationship to nucleic acid synthesis in intact and permeabilized cells. Cancer Res. 42: 4525-4531

Phelps WC, Yee CC, Munger K and Howley PM (1989) The human papillomavirus type $16 \mathrm{E} 7$ gene encodes transactivation and transformation functions similar to those of adenovirus E1A. Cell 53: 539-547

Prives C (1993) Doing the right things: feedback control and p53. Curr. Opinion in Cell Biology 5: 214-218

Prives C (1994) How loops, $\beta$ sheets, and $\alpha$ helices help us to understand p53. Cell 78: $543-546$

Ridley AJ, Paterson HF, Noble Mand Lane H (1988) Ras-mediated cell cycle arrest is altered by nuclear oncogenes to induce Schwann cell transformation. EMBOJ.7: $1635-1645$ 
Schaefer DI, Livanos EM, White AE and TIsty TD (1993) Multiple mechanisms of N(phosphonoacetyl)-L-aspartate drug resistance in SV40-infected precrisis human fibroblasts. Cancer Res. 53: 4946-4951

Serrano M, Gomez-Lahoz E, DePinho RA, Beach D and Bar-Sagi D (1995) Inhibition of Ras-induced proliferation and cellular transformation by $\mathrm{p} 16^{\mathrm{INK} 4}$. Science 267: $249-252$

Serrano M, Lee HW, Chin L, Cordon-Cardo C, Beach D and DePinho RA (1996) Role of the INK4a locus in tumor suppression and cell mortality. Cell 85: 27-37

Serrano M, Lin AW, McCurrach ME, Beach D and Lowe SW (1997) Oncogenic ras provokes premature cell senescence associated with accumulation of p53 and p16INK4a. Cell 88: 593-602

Sherr CJ and Roberts JM (1995) Inhibitors of mammalian G1 cyclin-dependent kinases. Gene \& Devel. 9: 1149-1163

Shi, YF, Glynn JM, Guilbert LJ, Cotter TG, Bissonnette RP and Green DR (1992) Role for c-myc in activation-induced apoptotic cell death in T-cell hybridomas. Science 257: 212-214

Smith ML, Chen I-T, Zhan Q, Bae I, Chen C-Y, Gilmer TM, Kastan MB, O'Connor PM and Fornace AJ (1994) Interaction of the p53-regulated protein GADD45 with proliferating cell nuclear antigen. Science 266: 1376-1380

Stark GR (1993) Regulation and mechanisms of mammalian gene amplification. Genetics in Cancer Res. 61: 87-113

Storey A, Pim D, Murray A, Osborn K, Banks L and Crawford L (1988) Comparison of the in vitro transforming activities of human papillomavirus types. EMBO J. 7: $1815-1820$

Tanaka N, Ishihara M, Kitagawa M, Harada H, Kimura T, Matsuyama T, LamphierMS, Aizawa S, Mak TW and Taniguchi T (1994) Cellular commitment to oncogeneinduced transformation or apoptosis is dependent on the transcription factor IRF1. Cell 77: $829-839$
Tlsty TD, Margolin BH and Lum K (1989) Differences in the rates of gene amplification in nontumorigenic and tumorigenic cell lines as measured by Luria-Delbruck fluctuation analysis. Proc. Natl. Acad. Sci. USA 86: 9441-9445

TIsty TD (1990) Normal diploid human and rodent cells lack a detectable frequency of gene amplification. Proc. Natl. Acad. Sci. USA 87: 3132-3136

Vogelstein B and Kinzler KW (1992) p53 function and dysfunction. Cell 70:523-526

Vojtek AB, Hollenberg SM and Cooper JA (1993) Mammalian Ras interacts directly with the serine/threonine kinase Raf. Cell 74: 205-214

Walker GC (1984) Mutagenesis and inducible responses to DNA damage in E. coli. Microbiol. Rev. 48: 60-93

Wang XW, Yeh H, Schaeffer L, Moncollin V, Egly J-M, Wang Z, Friedberg EC and Harris CC (1995) p53 modulation of RFIIH-associated nucleotide excision repair activity. Nature Genetics. 10: 188-195

Weinberg RA (1995) The retinoblastoma protein and cell cycle control. Cell 81:323330

Windle B, Draper BW, Yin X, O'Gorman S and Wahl GM (1991) A central role for chromosome breakage in gene amplification, deletion formation, and amplicon integration. Gene.Dev. 5: 160-174

Winston JT, Coats SR, Wang Y-Z and Pledger WJ (1996) Regulation of the cell cycle machinery by oncogenic ras. Oncogene 12: 127-134

Yin Y, Tainsky MA, Bischoff FZ, Strong LC and Wahl GM (1992) Wild-type p53 restores cell cycle control and inhibits gene amplification in cells with mutant $p 53$ alleles. Cell 70: $937-948$

Zhang K, Papageorge AG and Lowy DR (1992) Mechanistic aspects of signaling through Ras in NIH3T3 cells. Science 257: 671-674

Zullo JN and Faller DV (1988) p21 v-ras inhibits induction of c-myc and c-fos expression by platelet-derived growth factor. Mol. Cell. Biol. 8: 5080-5085 